\title{
Particularities regarding the evaluation of large equipment for explosive atmospheres
}

\author{
Gabriela Pupazan*, Tiberiu Csaszar, and Adriana Andris \\ ${ }^{1}$ National Institute for Research and Development in Mine Safety and Protection to Explosion - \\ INSEMEX, 32-34 G-ral Vasile Milea Street, Petrosani, Romania
}

\begin{abstract}
For placing electrical equipment that is protected by pressurized casings type of protection on the European market and for its use in spaces classified as explosive atmospheres, they must be evaluated and tested in accordance to relevant standards. The paper aims at presenting the peculiarities regarding the evaluation of large-scale equipment for explosive atmospheres. The first part of the paper refers to general requirements for large electrical equipment intended for use in explosive atmospheres. The requirements of pressurized casings type of protection and its technical principle of protection are shown in Part Two. As a conclusion, it has been pointed out that the disadvantage of energy consumed to provide protection to explosion provides the benefit of protection to explosion for large or complex structure equipment for which no other protection to explosion method can be applied.
\end{abstract}

\section{Introduction}

At the level of the European Community space [1], it is provided that equipment and installations intended for use in explosive atmospheres must have characteristics compatible with those of explosive atmospheres in which they are to function.

Large technical equipment intended for use in spaces where flammable substances are present in the form of gases, vapours, mists, but not continuously, can be effectively protected against explosion by pressurized casings type of protection.

The operation of electrical equipment protected by pressurized casings type of protection in areas with explosive atmospheres implies the maintenance of overpressure and dilution regime required by the use of the " $p$ " type of pressurized casing type of protection $[2,3]$.

For placing electrical equipment that is protected by pressurized casings type of protection on the European market and for its use in spaces classified as explosive atmospheres [4], it must be assessed and tested with regard to aspects relevant to the type of protection. The purging test is significant for explosion-protected equipment by "p" pressurized casings type of protection.

\footnotetext{
* Corresponding author: gabriela.pupazan@insemex.ro
} 
The purpose of this test is to verify the purge time by trial and its performance implies the staged use of high-density (carbon dioxide, argon) and low-density (helium) inert gases and monitoring the evolution of their concentration during the testing process.

\section{Explosive atmospheres}

Since explosions can cause immeasurable human losses and material damage, the risk assessment of explosions [5, 6] and establishment of appropriate measures to reduce it to acceptable levels according to current standards and regulations is of particular importance for human health and safety and for protection of property.

Gaseous explosive atmospheres are mixtures of flammable substances [7, 8], in form of fine gas dispersion with air, under normal atmospheric conditions, for which the ignition burns violently (explosively) from source to the entire volume of mixture.

The release of flammable substances into the atmosphere, followed by their ignition, can produce a wide variety of thermal and dynamic effects.

Arising of explosive gas atmospheres in mixture with air as well as the ignition and combustion of these preformed mixtures is shown below:

In phase I, the release of the flammable substance into the atmosphere takes place by diffusion or gas stream, and in the second stage gases or vapours are mixed at molecular level with air, forming explosive mixtures within the limits of lower and higher explosive concentrations. In stage III, the preformed mixture is ignited by a source of ignition (sufficiently high in terms of temperature and energy) and in the IV stage the actual exothermic reaction takes place, its character being defined by the reaction rate: burning, explosion (deflagration, detonation) with high temperature flame, heat release and pressure development [5].

\subsection{Types of explosion protection for electrical equipment}

The emergence of explosion protection types was individually induced by critical situations with regard to safety regime for the operation of technical equipment in areas with explosive atmospheres, but also by the foresight of imminent technical progress.

Explosion protection type $[9,10,11]$ is represented by those specific measures applied to electrical and / or non-electrical equipment to avoid the ignition of an ambient explosive atmosphere [12].

Constructively, electrical equipment may have several types of protection specified by the manufacturer by tag as required by the applicable standards.

Each type of protection is based on a technical solution for implementation of explosion protection. The highest incidence technical solution for implementing explosion protection with is based on separation of hazardous atmosphere from parts of the equipment, that can become a source of ignition.

Performance of different types of protection can be expressed by using classification by categories or levels of protection. See figures 1 to 4 . 


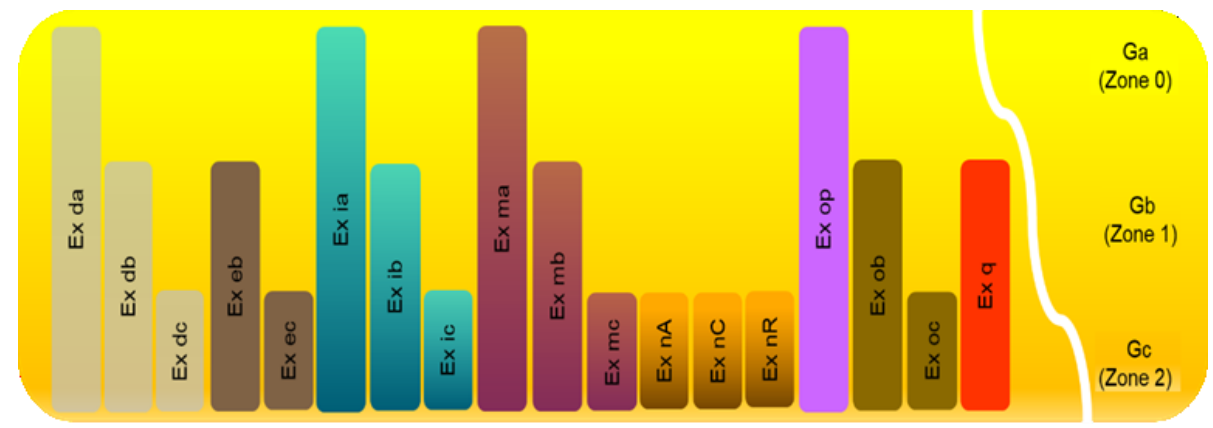

Fig. 1 Protection levels associated with types of protection applied to explosive gas atmospheres

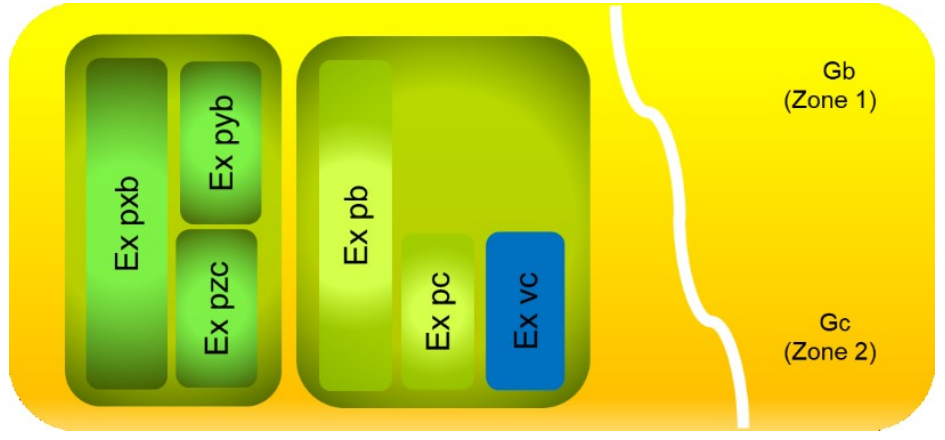

Fig. 2 Protection levels associated with pressurized casings type of protection applied to equipment used in gaseous explosive atmospheres

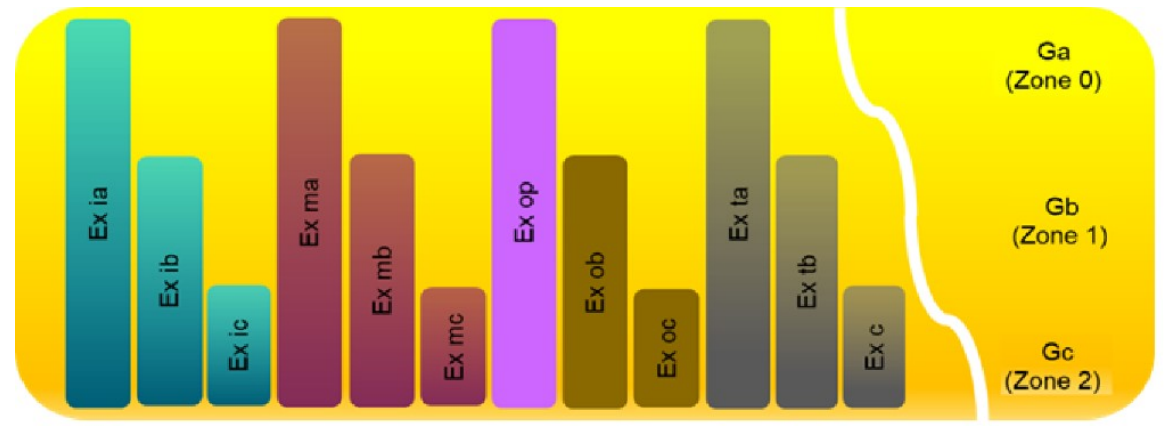

Fig. 3 Protection levels associated with the types of protection applied to explosive atmospheres with dust

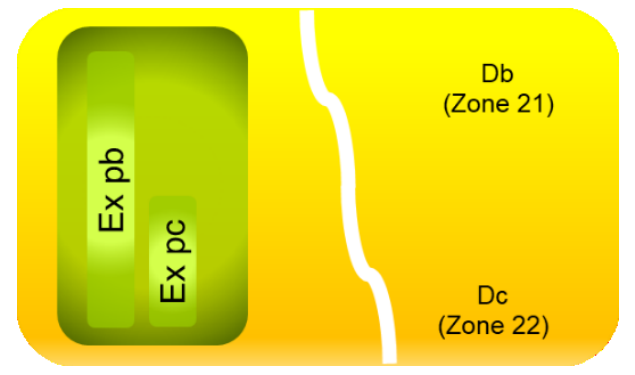

Fig. 4 Protection levels associated with pressurized casings type of protection applied to explosive atmospheres with dust 
Types of protection for electrical equipment intended for use in explosive atmospheres generated by flammable gases, vapours or mists may be divided according to presence of the ignition source and of the potentially explosive atmosphere, as follows:

(a) Types of protection that allow direct contact between the ignition source and the hazardous atmosphere ("d" anti-deflagration casing, "i" intrinsic safety and "non-flammable "nC") have the highest degree of safety.

b) Types of protection which do not allow direct contact between ignition source and the dangerous atmosphere (oil immersion "o", "p" pressurized casing, "q" dust embedding, encapsulation "m").

c) Types of protection that by construction attempt to eliminate the source of ignition under specified conditions ("e" increased safety, non-flammable "nA") have the lowest degree of safety.

\section{Particularities of security requirements for pressurization protection technique}

\subsection{Equipment protected by " $p$ " pressurized casings}

The principle of " $\mathrm{p}$ " pressurized casings type of protection consists in separating the potentially explosive atmosphere from the ignition source by maintaining an overpressure inside the casing by means of a protective gas (inert air or gas).

It is generally applicable to large electrical equipment that may produce sparks, electric springs, or generate hot interior surfaces in normal operation.

Pressure protection is divided into three protection levels (pxb, pyb and pzc) that are chosen according to equipment protection level (EPL) required for an external gaseous explosive atmosphere ( $\mathrm{Mb}, \mathrm{Gb}$ or $\mathrm{Gc})$, if there is a possibility of internal releases and if the equipment inside the pressurized casing can produce ignition.

This type of protection provides a level of security for use in area 1 or 2 , meeting the requirements for equipment categories 2 or 3 (fig. 5).

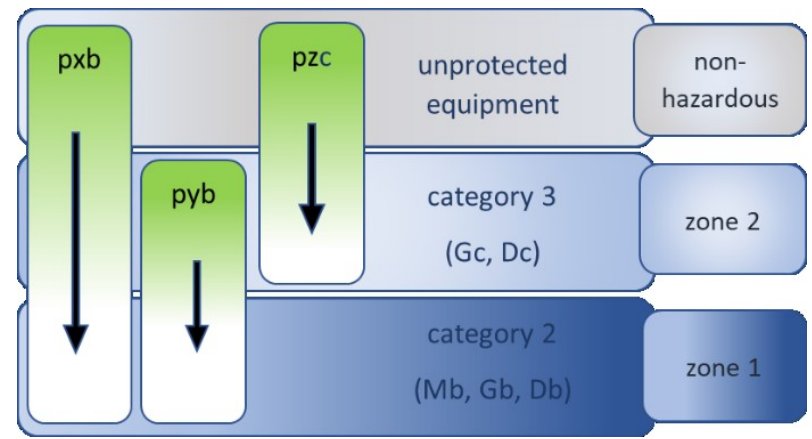

Fig. 5 Levels of "p" pressurized casings type of protection associated with the equipment categories and corresponding areas

This type of protection is the only one that consumes energy to provide explosion protection. Energy consumption is required to carry out the purging, circulation of the protective gas, to maintain overpressure inside the casing and to monitor the pressure.

According to [12] the temperature class for equipment protected by "p" pressurized casings type of protection, should be established as follows: for "pxb" or "pyb" protection level, temperature class must be based on the hottest external surface of the casing or the 
hottest internal surface of a component part, and for the "pzc" protection class, temperature class must be based on the hottest external surface of the casing.

Pressurization represents the protection technique that prevents penetration of external atmosphere inside a casing by maintaining an internal gas at a pressure higher than that of the outside atmosphere, which can be achieved either by continuous flow of the protective gas or by compensation of losses.

Before being energized, the pressurized casing must be purged with a quantity of protective gas of at least five times the internal volume of capsule and piping, thereby creating an overpressure that is maintained during operation and prevents external atmosphere explosive gases and vapours from entering (pressurization with compensation of losses).

Continuous circulation of protective gas (dilution pressurization) is the technique of maintaining an overpressure inside a pressurized capsule by continuously flowing the protective gas into the casing after purging.

In addition to tag in [12], labelling of the pressurized equipment must contain: free internal volume; nature of protective gas; minimum amount of gas required for purging.

\subsection{Equipment protection by pressurized room " $p$ " and artificially ventilated room " $v$ "}

Equipment protection by pressurized room "p" and artificially ventilated room "v" are described separately [13] but can be combined to provide protection against hazards when required.

\subsection{Equipment protection by pressurized room "p"}

Equipment protection by pressurized room involves containment of non-explosion-proof equipment (except for security devices characteristic to pressurization which must be protected to explosion by another type of protection) in a room where overpressure is produced and maintained in such a manner that outside explosive atmosphere cannot penetrate inside the room. This pressurized room is designed to allow access for surveillance staff.

Depending on where they are installed, these pressurized rooms provide a "pb" level of protection for areas requiring EPL Gb or Db equipment (Zone 1 or Zone 21) or a "pc" protection level for areas requiring EPL Gc or Dc equipment (Zone 2 or Zone 22).

\subsection{Equipment protection by artificially ventilated room "v"}

This equipment explosion protection technique consists in placing it in a room where artificial ventilation is carried out and maintained to dilute the concentration of gas or vapour flammable substances within the room to less than $25 \%$ of the lower flammability limit.

Artificially ventilated rooms may be located either in a non-hazardous area or in a hazardous area requiring EPL Gc equipment (Zone 2), in which case they must provide "vc" protection level.

Within these artificially ventilated rooms, hazardous atmosphere can be reduced either from a level requiring EPL $\mathrm{Gb}$ or Gc equipment to a level that does not require explosionproof equipment or from a level requiring EPL Gb equipment to a level that requires EPL Gc equipment.

Artificial ventilation can be applied to the entire room volume or can be applied locally to a specific location in the room, for example in the case of an internal source of emission. 


\subsection{Aspects regarding the testing of large-scale equipment protected by pressurized casing/ room}

Tests are a complementary step beside assessment in the process of certification of equipment protected by pressurised casing/room.

The purpose of tests is to practically show compliance with performance requirements set by specific standard.

Depending on the pressurization method chosen for the equipment, certain type tests are applicable (fig. 6).

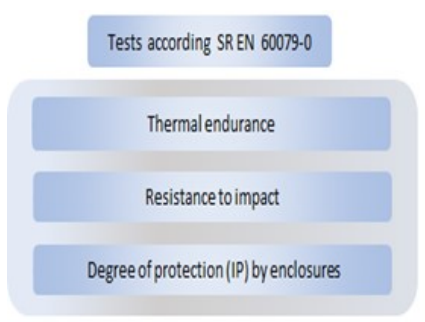

Fig. 6 Type tests for equipment protected by pressurized casing / room

The standard atmospheric conditions in which Ex equipment can be tested are [2]: temperature $-20^{\circ} \mathrm{C} \div+60^{\circ} \mathrm{C}$; pressure of $80 \mathrm{kPa}(0.8$ bar $)$ to $110 \mathrm{kPa}(1.1 \mathrm{bar})$; air with a normal oxygen content, usually $21 \% \mathrm{v} / \mathrm{v}$.

Measuring the maximum surface temperature is based on an operating ambient temperature of $-20^{\circ} \mathrm{C}$ to $+40^{\circ} \mathrm{C}$, unless otherwise specified in the manufacturer's documents.

Tests to be considered according to standard [12] aim to highlight the mechanical protection characteristics, the usual degree of protection and structural stability of plastics and elastomers.

Tests to be considered according to [2] and [13] aim to highlight the functional characteristics of explosion protection by pressurized casing/room, such as: minimum guaranteed overpressure, purge time, maximum overpressure resistance, etc.

The requirements set by [2] are for pressurized carcasses containing a limited release source of a flammable substance but not for:

- pressurized casings if the containment system can release air with an oxygen content higher than normal, or oxygen in combination with inert gas where oxygen is higher than $21 \%$.

- pressurized rooms or analysis rooms;

- pressurized compartments used when explosive or pyrotechnic substances are present;

- pressurized casings used in the case of hybrid gas/vapour mixtures and combustible dust;

- pressurized casings used when pyrophoric substances, such as explosives or fuels containing their own oxidants, are pressurized carcasses with an internal source of flammable dust release. 


\section{Conclusions}

Aspects that recommend the use of pressurized casing/room type of protection have been highlighted.

Explosion protection performance was shown, compared to other types of protection against equipment level of protection, respectively ATEX category.

It has been pointed out that the disadvantage of energy consumed to provide explosion protection is offset by the benefit of explosion protection for large equipment or equipment having a complex structure for which no other explosion protection method can be applied.

It has also been pointed out that in addition to its pressurization function, protective gas can also be used to take over excess heat (coolant) produced by the protected equipment during operation.

Among others, one of the most important advantages offered by the use of pressurized casing/room type of protection is to protect equipment intended for use in combustible dust atmospheres.

\section{References}

1. Directive 2014/34/EU (2014)

2. Standard EN 60079-2 (2018)

3. Ionescu J., Burian S., Darie M., Csaszar T., Andriș A., (2008)

4. Romanian Government Decision no. 245, (2016)

5. Simion S., Vasilescu D., et. al.., Explosion risk, Europrint, Oradea Publishing House, ISBN 973-7735-08-0, (2004)

6. Grabara J., Dura C., Drigă I., Vol. 9 (4) , pp. 344-350, (2016)

7. Pradyot P., A Comprehensive Guide to the Hazardous Properties of Chemical Substances, Third Edition, John Wiley \& Sons, Inc. Publishing House, ISBN-13: 9780-471-71458-3, (2007)

8. Dura C., Dobre B. O., Q.A.S.J., Vol. 16 (149), pp. 62-67, ISSN 1582-2559, (2015)

9. Bottril G., Chueyne D., Vijayaraghavan G., Practical electrical equipment and installations in hazardous areas, Elsevier Publishers, 149-150, (2005)

10. Burian S., Ionescu J., Darie M., Csaszar T., Andriș A., Requirements for Installations in Areas with Explosive Atmosphere, Other than Mines, (in Romanian), INSEMEX Petrosani Publishing House, Romania, (2007)

11. Căprar I.N., Burian S.,et. al., Technical equipment for potentially explosive atmospheres Group II, Europrint- Oradea publishing House, ISBN 973-86428-0-9 /, (2003)

12. Standard EN 60079-0 (2018)

13. Standard EN 60079-13 (2018) 